\title{
Proprietary science, open science and the role of patent disclosure: the case of zinc-finger proteins
}

\author{
Subhashini Chandrasekharan ${ }^{1}$, Sapna Kumar ${ }^{3}$, Cory M Valley ${ }^{4}$, and Arti Rai ${ }^{1,2}$ \\ ${ }^{1}$ Center for Public Genomics, Center for Genome Ethics, Law \& Policy, Institute for Genome \\ Sciences \& Policy, Duke University, Durham, North Carolina 27708, USA \\ ${ }^{3}$ Chambers of the Hon. Kenneth Ripple, US Court of Appeals for the Seventh Circuit, Chicago, Illinois \\ 60604, USA \\ ${ }^{4}$ University of Maryland School of Law, Baltimore, Maryland 21201, USA.
}

Recent advances in the ability to engineer customized zinc-finger proteins (ZFPs), which can bind virtually any DNA sequence of interest, have generated excitement among both academic and industrial researchers. Engineered ZFPs can be used to alter chromatin structure, regulate endogenous gene expression levels, and introduce targeted modifications in genes. In one salient case, a chimeric zinc finger-nuclease (ZFN) successfully stimulated homologous recombination and thus repaired a mutant IL2R $\gamma(I L 2 R G)$ gene associated with X-linked severe combined immune deficiency (SCID) (1). ZFP-based therapeutics developed by Sangamo Biosciences for diabetic neuropathy and peripheral arterial disease are undergoing phase 1 and 2 clinical trials (2), and a ZFN-mediated approach for disrupting the CCR5 receptor in patient T cells as a strategy to increase resistance to HIV is in preclinical development (3). These advances have given researchers hope that ZFP- and ZFN-based approaches may help improve both the efficiency and the precision of gene therapy. Other potential commercial applications for ZFPs include plant genetic engineering, the production of biopharmaceutical molecules such as growth factors and antibodies, and the nascent field of synthetic biology. ZFN technology has also been used successfully to make targeted gene modifications in several model organisms such as Drosophila (4), C. elegans (6), plants $(7,8)$ and most recently zebrafish $(9,10)$, illustrating the range of uses for ZFNs in basic research as powerful molecular biology tools.

As might be expected with any research platform that has many potential commercial uses, a large patent estate now covers both the engineering and the use of ZFPs. Notably, the patent estate was initially owned by several different companies and academic institutions, thereby creating the possibility that subsequent users and developers would face prohibitive costs in negotiating multiple licenses - the classic scenario of a patent "anticommons" (11). However, one company, Sangamo, has now consolidated the majority of this patent estate. The dominant patent position held by Sangamo has raised the recurrent question of whether a company's monopoly control over an important and versatile research platform will ultimately help or hinder optimal development of that platform. Because such development can occur within both the private and public sectors, there is also the subsidiary issue of whether patents will be enforced against academic researchers in the same manner as they might be enforced against private-sector competitors. 
Previous studies (12) suggest that academic researchers do not seem concerned about being sued by private-sector patentees. For example, a survey of academic biomedical researchers found that only $5 \%$ report checking for patents related to their research (13). These studies further indicate that private-sector patent owners practice "rational forbearance" and do not sue academic researchers because of the difficulties and disadvantages of asserting patent rights in such circumstances $(14,15)$. Currently, the conventional view is that academic biomedical research is more likely to be impeded by lack of access to privately held research inputs such as materials, data and know-how than by patents $(12,13,16,17)$.

To explore the impact of ZFP patents, and specifically Sangamo's dominant patent position, on academic and commercial research and development, we systematically created a map of existing patents in the ZFP arena, presented here for the first time. We also conducted interviews with academic researchers in the field to develop a nuanced understanding of the complex interactions between private and public ZFP research endeavors. Our findings are consistent with the view that, for academics, lack of access to information and materials is a greater problem than the threat of patent lawsuits. However, because some of the access problems would have been alleviated if statutory obligations regarding patent disclosure had been met, our research also suggests the heretofore unrecognized possibility of an overlap between patents and access to information and research materials. More complete patent disclosure might also have obviated the need to generate various open-science alternatives to the Sangamo platform.

\section{The ZFP/ZFN intellectual property landscape}

Using a keyword-based search query (see Fig. 1), we determined that the number of ZFPrelated patents granted in the United States increased steadily from 1997 to 2001, with four patents granted in 1997 and 26 granted in 2001. Since 2001, the numbers of patents issued each year has remained fairly constant, and to date the largest number of patents (28) was granted in 2006 (see Fig. 1). The search query similarly identified 189 pending US applications for the same time period (data not shown). Sangamo Biosciences is the single largest owner of issued US patents on ZFPs (42 patents). But a number of other institutions are also well represented; for example, the Massachusetts Institute of Technology (MIT) owns 13 patents and the Scripps Institute owns 9 patents (see Fig. 2).

From the pool of patents generated by our search query, patents that directly pertain to the engineering and use of engineered zinc-finger proteins were identified through analysis of the claims (see Supplementary Table 1). The 42 patents owned by Sangamo include 8 patents on rules and libraries for constructing sets of 'two-zinc-finger' domains, each of which can bind to a specific sequence of six nucleotides. These were previously owned by UK-based Gendaq Ltd., which was acquired by Sangamo in July 2001 (18).

Sangamo has also actively licensed intellectual property (IP) from a number of academic institutions. This IP includes five patents from MIT, three from the Scripps Institute, two from Harvard University and six from Johns Hopkins University (JHU) (18). The patents licensed from MIT, Scripps and Harvard and two of the six patents licensed from JHU are a subset of the patents listed in Supplementary Table 1. An additional four patents licensed from JHU relate to ZFN technology (see Supplementary Table 2). Sangamo acquired these technologies from MIT, Harvard, the California Institute of Technology (Caltech) and JHU under worldwide exclusive licenses for all fields of use, including the rights to sublicense (18). The only exception to this pattern is for patents licensed from the Scripps Institute, where the licenses exclude Sangamo from specific fields of use, including diagnostics, therapeutics and genetic engineering in plants (18). Thus, although initial ownership of ZFP-related patents was 
dispersed, creating the potential for high transaction costs and anticommons effects, Sangamo's energetic acquisition and licensing activity has consolidated many of the requisite patent rights.

Four patents on the engineering and design of the FokI endonuclease, which is used to generate designer ZFNs, have been licensed from JHU (see Supplementary Table 2). Sangamo

Biosciences recently obtained exclusive rights to related technologies for genetic engineering and gene modification using ZFNs from the University of Utah, US Application no.

US20050208489A1: Targeted chromosomal mutagenesis using zinc finger nucleases, and from Caltech, US Application no. US20050026157A1: Use of chimeric nucleases to stimulate gene targeting (18). Sangamo also purchased ZFN-related IP from STELL Inc. in 2004, US20030232410A1: Methods and compositions for using zinc finger endonucleases to enhance homologous recombination (19). Assuming that these applications are granted, Sangamo will have consolidated key IP surrounding the use of ZFNs for gene correction and gene repair in the United States.

An analysis of the different categories of patents (see Supplementary Table 1 and Supplementary Table 2) reveals that at least 24 of the 55 patents owned by or licensed exclusively to Sangamo cover technologies for the design, selection and optimization of engineered ZFPs. Our analysis also indicates that several patents owned by Sangamo are foundational for the ZFP field, with limited possibilities for a 'workaround'. Perhaps most salient is a trio of patents (US Patent nos. 71777766, 6785613 and 6453242) that broadly claim the dominant 'modular' strategy for ZFP design (at least with respect to three-finger ZFPs that bind to sequences containing nine nucleotides). This modular strategy relies on assembling a multifinger protein from individual zinc-finger modules where each module has been determined to bind specifically to a particular three-nucleotide subunit and, ideally, to the subunit as further specified by its location within the sequence of nine nucleotides. Also significant is US Patent no. 6794136, which covers "iterative optimization in the design of binding proteins": this patent broadly covers methods for further improving binding specificity once a ZFP candidate for a particular nucleotide sequence has been identified.

More than three-quarters of the patents owned by or licensed to Sangamo (44 of 55) concern inventions that could be categorized as research methods and tools, with 24 patents covering methods for the design and selection of ZFPs and another 20 patents covering methods to regulate or modify endogenous gene expression using engineered ZFPs and/or ZFP transcription factors. The earliest issued patent in this set will not expire until 2018, making it unlikely that academic or commercial researchers will be able to wait for the technologies to pass into the public domain.

\section{Impact on commercial R\&D}

The ZFP patent landscape that we have created confirms Sangamo's dominant position in ownership of patents covering relevant research tools and methods, including foundational patents on enabling technologies. This position could have at least two benefits. First, a dominant patent position facilitates Sangamo's ability to attract private capital (20). Given Sangamo's considerable R\&D expenses (21) and lack of marketable products, this private capital is necessary even though Sangamo has also received some federal funding, including two grants totaling nearly \$4 million from National Institute of Standards and Technology. Not surprisingly, Sangamo executives have repeatedly stated that a strong patent portfolio has been vital to the company's success $(22,23)$. Second, as mentioned earlier, Sangamo's consolidation of relevant IP rights may ease negotiation cost burdens for commercial entities that want to work in this area, as they will have to negotiate licenses with only one institution instead of several. Such licensing negotiations may be an option that Sangamo actively seeks. Economic theory would suggest that a rational, profit-maximizing monopolist that cannot develop a 
platform by itself in certain areas of application will often be inclined to license, so as to promote development in those areas by others $(24,25)$. Collaboration and licensing might be particularly desirable for a small company such as Sangamo that has limited capacity to pursue in-house development for all possible applications of its technology.

However, economic theory has also identified a variety of situations in which increased negotiation costs in concluding licensing deals, as well as other distortions, could impede a monopolist's optimal deployment of a research platform (24). As an empirical matter, the historical record shows that patents that conferred monopoly control over foundational technologies in the aircraft and automobile industries impeded development (26).

Sangamo's out-licensing strategies provide support for both the optimistic and the pessimistic views of monopoly control. For application areas outside Sangamo's main focus on ZFP-based medical therapeutics, the company has granted several companies access to its IP. For example, through its "Enabling Technology Program," Sangamo has longstanding collaborations with Pfizer, Amgen and NovoNordisk for more efficient pharmaceutical production of proteins (18). More recently, Sangamo granted Dow AgroSciences exclusive rights (including sublicensing rights) to ZFP and ZFN technologies for modifying plant genomes and altering plant gene expression (2).

In contrast, several reports indicate that the inability to conclude a licensing arrangement with Sangamo played a crucial role in the failure of the plant biotechnology start-up Phytodyne, founded by researchers at Iowa State University. Phytodyne received significant venture capital investment and financial support from the state of Iowa and was developing plant genetic engineering applications viewed as highly promising by the industry. It is difficult to ascertain the long-term impact of this failure on innovation in plant genetic engineering, particularly because Dow is now actively engaged in similar R\&D. However, to the extent that small enterprises such as Phytodyne may be better positioned to pursue breakthrough innovation than larger firms like Dow $(27,28)$, this example illustrates the potential negative effects of patent monopolies.

\section{Impact on academic research}

Academia provides an important venue for improvement of research platforms, in addition to the commercial sector. As noted earlier, survey research indicates that, with respect to such platforms, academic scientists routinely ignore patents, and private-sector patentees correspondingly refrain from enforcing their patents $(12,16,17)$. To determine whether Sangamo patents were impeding academic research and, if so, to what extent, we interviewed a number of prominent ZFP researchers, including researchers who have licensed patents to and collaborate with Sangamo. Academic scientists indicated that they routinely used patented technologies owned by Sangamo without securing a license. Thus, consistent with prior work, we found that ZFP researchers engage in infringement under the expectation that Sangamo will refrain from suing academics.

Several scientists did, however, express concern about lack of access to Sangamo's ZFPs and ZFNs. Researchers would like to collaborate with Sangamo because it possesses a platform capable of engineering ZFPs for many triplet nucleotide sequences as well as the information necessary for performing further optimization that is sometimes required to obtain highspecificity ZFPs and ZFNs. Sangamo does not disclose detailed information about this proprietary platform. Additionally, although Sangamo has signed material transfer agreements with several academic research groups to provide ZFPs and/or ZFNs, it appears to be highly selective in its choice of collaborators (22). 
Sangamo recently entered an agreement with Sigma-Aldrich under which Sigma will use Sangamo's technology platform to provide ZFP and ZFN reagents that bind any DNA sequence in which a researcher is interested $(2,21)$. Although this agreement is likely to improve academic researchers' access to Sangamo's highly specific ZFPs (at least to the extent that researchers can afford to pay Sigma's $\$ 25,000$ fee), researchers will still be unable to access Sangamo's platform directly.

\section{The role of patent disclosure}

Sangamo's unwillingness to disclose proprietary know-how about its platform is not unusual - secrecy is a routine competitive strategy in the commercial sector. More problematic is the strong possibility that at least part of this proprietary information should, under standard doctrines of patent disclosure, be disclosed in the Sangamo patents themselves. Patent law requires that a patent teach a "person having ordinary skill in the art" how to practice the claimed invention. According to several ZFP scientists with whom we spoke, actually practicing the trio of foundational patents that cover the design of "specific" three-finger proteins would require access to Sangamo's proprietary database or 'rule set' on matching ZFP modules with particular three-base DNA subunits. These Sangamo patents do not, however, disclose any such database or rule set. Thus, in this case, even though these patents are not being asserted against scientists, they confer 'practical excludability' because they do not meet the statutory obligation of enabling scientists to practice the inventions that the patents cover (13).

The Sangamo case study also highlights the fact that patents and access to tangible materials and know-how, which are thought of as two distinct problems, might actually overlap in interesting ways. If the 'patent bargain' of exclusivity in exchange for disclosure were being satisfied, problems encountered by academics over access to physical materials and data might be alleviated. The patent disclosure would provide at least some of the information not disclosed by scientific publication that is necessary to make such materials independently. This is especially salient because academic researchers report that a major reason for not making research materials independently is "inability" to do so, due to lack of equipment, information or expertise $(12,13,17)$. Improving patent disclosure would not resolve the problem that, absent a formal research exemption from infringement liability in patent law, using the statutorily required patent disclosure to make or practice the invention for academic research would technically constitute willful infringement. However, given the reluctance of companies to sue academic researchers, concerns about infringement may be more hypothetical than real.

Unfortunately, problems associated with inadequate patent disclosure in biotechnology are likely to get worse rather than better. Even if it is enforced incompletely (29), the high standard of disclosure for DNA sequence patents has historically made disclosure in biotechnology better than in other areas. However, as biotechnology begins to look more like information technology, with the ZFP databases and design rule sets providing one illustration of this trend, the notoriously poor disclosure standards associated with information technology may be poised to infiltrate biotechnology (30). Notably, as many commentators have pointed out, the case law that governs information technology patents often allows broad, vague claims that are unsupported by adequate disclosure $(31,32)$.

Policing the patent bargain of exclusivity in exchange for appropriate disclosure should be the function of the US Patent \& Trademark Office (USPTO). But given the high volume of pending patent applications and the rapidly changing state of the art, especially in biotechnology, developing mechanisms by which experts outside the USPTO could help flag problems of underdisclosure (either during the examination process or post-grant) would be a welcome improvement. Whether academic researchers would be inclined to participate in such mechanisms is not clear. Because academic scientists largely rely on peer-reviewed 
publications rather than patent disclosures for know-how, and rarely experience patents as threatening or impeding their research activities, there may be little incentive for the academic community to engage in such an outside review process.

\section{Open-science alternatives}

The Zinc Finger Consortium, a prominent academic program founded by ZFP researchers J. Keith Joung and Dan Voytas, was created in part to address concerns about access to materials and Sangamo's proprietary databases (33). Two web-based tools for identifying potential ZFP target sites in DNA sequences are also freely available, Zinc Finger Tools (34), developed by Carlos Barbas's team at the Scripps Research Institute, and a second program, Zinc Finger Targeter (ZiFiT), designed by members of the Consortium (35). The Consortium has also generated an archive of plasmids encoding over 140 zinc-finger modules (derived from publicly available archives of zinc fingers) that bind specific nucleotide triplets. The plasmids are made available to all interested academic researchers via the nonprofit distribution service AddGene. These various finger modules have been reported to bind to many ANN and GNN triplets and to CNN and TNN triplets to a lesser degree. These zinc-finger modules appear to infringe various Sangamo patents, but nevertheless Sangamo has not blocked their distribution for research purposes. Reagent availability through the Consortium is subject to a vaguely worded licensing agreement stating that certain uses of the zinc-finger modules requires a license from Sangamo (36). But the extent to which Sangamo attempts to enforce this clause is unclear. Recent work from Consortium labs (37) has furthermore demonstrated that the efficacy rate for engineering ZFPs using these modules is significantly lower than the more robust rates originally reported in the literature by other groups $(38,39)$. Thus, it may be that actual enforcement against academic or commercial users of Consortium modules is unnecessary because most commercial applications would be likely to require the higherefficiency ZFPs produced by Sangamo.

In July 2008, Keith Joung and his colleagues improved on prior Consortium technology by reporting a novel and robust method for generating custom ZFNs with activities superior to those produced by the previously standard modular design approach and with activities and toxicities comparable to those of an optimized ZFN produced by the proprietary Sangamo method $(33,40)$. The presence of roughly comparable proprietary and open-science alternatives may produce a productive tension resembling the competition between the public and private human genome sequencing endeavors (41). Alternately, it may result in peaceful coexistence of the two platforms, as illustrated by the diffusion of microarray technologies. Open approaches for disseminating 'spotted glass' microarray technology pioneered by Pat Brown and colleagues in the early 1990s aimed to offer academic researchers a lower-price alternative to Affymetrix's costly microarrays $(42,43)$. Although Affymetrix sued commercial developers of spotted microarray technology, it never asserted its IP rights against academic users (43, 44). A decade later, both platforms continue to be widely used in academic research. An early response from Sangamo suggests that it does not perceive OPEN as a major challenge. Indeed, Sangamo has indicated that the coexistence of the open-science alternative may even be favorable to its position, as having more academic scientists performing ZFP-based research may enhance the value of the company (21). With Sangamo's patents broadly covering uses such as regulation of gene expression in different organisms, commercial development of downstream applications would almost always require rights to use IP controlled by Sangamo.

The reagents associated with the OPEN platform will be made publicly available to academic researchers at a price of approximately $\$ 5,000$ a set $(21,45)$. Not only will this be more affordable to academic researchers than the $\$ 25,000$ charged by Sangamo/Sigma, but the availability of OPEN reagents may eventually provide sufficient competition to cause a reduction in the price of the Sangamo/Sigma reagents. 


\section{Conclusions}

Sangamo's strategic acquisition of patents has given the company a powerful monopoly over an important platform technology. As economic theory would predict, Sangamo has often (but not always) licensed its platform technology in a manner that is both profit maximizing and likely to enhance social benefit. To date, Sangamo has also tolerated an open-science alternative to its proprietary platform. The coexistence of open and proprietary alternatives may be productive or, at a minimum, peaceful.

Two features of the ZFP/ZFN case are particularly noteworthy. First, because of problems with patent disclosure, patents may effectively be posing a barrier to academic research in this field. Second, resolving deficiencies in patent disclosure could mitigate the problem of academic access to physical materials and know-how, perhaps even obviating the need to develop openscience alternatives. Thus our study raises the possibility that even when academics are not defendants in patent suits, and enjoy a de facto (if not de jure) exemption from patent infringement liability, the patent system may nonetheless be failing to fulfill the constitutional mandate that patents "promote the progress of...the useful Arts."

\section{Supplementary Material}

Refer to Web version on PubMed Central for supplementary material.

\section{Acknowledgments}

The authors would like thank R. Cook-Deegan and K. Joung for helpful comments and criticisms. The authors gratefully acknowledge the support of the National Human Genome Research Institute and the Department of Energy (CEER Grant P50 HG003391, Duke University Center of Excellence for ELSI Research.

\section{References}

1. Urnov FD, et al. Nature 2005;435:646-651. [PubMed: 15806097]

2. Sangamo Biosciences Annual SEC filing Form 10K 2008. [accessed 23 January 2009]. http://www.secinfo.com/d14D5a.t1bzr.d.htm

3. Perez EE, et al. Nat. Biotechnol 2008;26:808-816. [PubMed: 18587387]

4. Beumer K, Bhattacharyya G, Bibikova M, Trautman JK, Carroll D. Genetics 2006;172:2391-2403. [PubMed: 16452139]

5. Bibikova M, Beumer K, Trautman JK, Carroll D. Science 2003;300:764. [PubMed: 12730594]

6. Morton J, Davis MW, Jorgensen EM, Carroll D. Proc. Natl. Acad. Sci. USA 2006;103:16370-16375. [PubMed: 17060623]

7. Wright DA, et al. Plant J 2005;44:693-705. [PubMed: 16262717]

8. Lloyd A, Plaisier CL, Carroll D, Drews GN. Proc. Natl. Acad. Sci. USA 2005;102:2232-2237. [PubMed: 15677315]

9. Meng X, Noyes MB, Zhu LJ, Lawson ND, Wolfe SA. Nat. Biotechnol 2008;26:695-701. [PubMed: 18500337]

10. Doyon Y, et al. Nat. Biotechnol 2008;26:702-708. [PubMed: 18500334]

11. Heller MA, Eisenberg RS. Science 1998;280:698-701. [PubMed: 9563938]

12. Walsh JP, Cho C, Cohen WM. Res. Policy 2007;36:1184-1203.

13. Cohen, WM.; Walsh, JP. Innovation Policy and the Economy. Jaffe, AB.; Lerner, J.; Stern, S., editors. Vol. Vol. 8. Chicago: University of Chicago Press; 2007. p. 1-30.

14. Fore J Jr, Wiechers IR, Cook-Deegan R. J. Biomed. Discov. Collab 2006;1:7. [PubMed: 16817955]

15. Pressman L, et al. Nat. Biotechnol 2006;24:31-39. [PubMed: 16404390]

16. Campbell EG, et al. J. Am. Med. Assoc 2002;287:473-480.

17. Walsh JP, Cho C, Cohen WM. Science 2005;309:2002-2003. [PubMed: 16179461] 
18. Sangamo Biosciences Annual SEC filing Form 10K 2007. [accessed 23 January 2009]. http://www.secinfo.com/dsvrp.u4fp.htm

19. Sangamo Biosciences Quarterly SEC filing Form10Q 2004. [accessed 23 January 2009]. http://google.brand.edgar-online.com/displayfilinginfo.aspx?

FilingID $=3125032-801-132173 \&$ type $=$ sect $\&$ TabIndex $=2 \&$ companyid $=72223 \& p p u=\%$ 252fdefault.aspx \%253fsym\%253dSGMO

20. Mann R, Sager T. Res. Policy 2007;36:193-208.

21. Pearson H. Nature 2008;455:160. [PubMed: 18784697]

22. Scott CT. Nat. Biotechnol 2005;23:915-918. [PubMed: 16082353]

23. Kaiser J. Science 2005;310:1894-1896. [PubMed: 16373552]

24. Farrell J, Weiser P, Harv J. Law Technol 2003;17:85-134.

25. Kitch EJ. Law Econ 1977;20:265-290.

26. Merges R, Nelson R. Columbia Law Rev 1990;90:839-916.

27. Acs, Z.; Audretsch, D. Innovation and Small Firms. Cambridge, Massachusetts, USA: MIT Press; 1990.

28. Audrestsch, D. Innovation and Industry Evolution. Cambridge, Massachusetts, USA: MIT Press; 1995.

29. Holman C. Albany Law J. Sci. Technol 2007;17:1-85.

30. Rai A, Boyle J. PLoS Biol 2007;5:e58. [PubMed: 17355173]

31. Bessen, J.; Meurer, M. Patent Failure. Princeton, New Jersey, USA: Princeton University Press; 2008.

32. Burk D, Lemley M. Berkeley Technol. Law J 2002;17:1155-1206.

33. Wright DA, et al. Nat. Protoc 2006;1:1637-1652. [PubMed: 17406455]

34. Mandell JG, Barbas CF III. Nucleic Acids Res 2006;34(Web Server issue):W516-W523. [PubMed: 16845061]

35. Sander JD, Zaback P, Joung JK, Voytas DF, Dobbs D. Nucleic Acids Res 2007;35(Web Server issue):W599-W605. [PubMed: 17526515]

36. Zinc Finger Consortium Sets from AddGene (AddGene Licenses for Plasmids with Sangamo ZincFinger Technology). [accessed 23 January 2009].

http://www.addgene.org/pgvec1?f=a\&cmd=showfile\&file=sangamo

37. Ramirez CL, et al. Nat. Methods 2008;5:374-375. [PubMed: 18446154]

38. Segal DJ, et al. Biochemistry 2003;42:2137-2148. [PubMed: 12590603]

39. Bae KH, et al. Nat. Biotechnol 2003;2:275-280. [PubMed: 12592413]

40. Maeder ML, et al. Mol. Cell 2008;31:294-301. [PubMed: 18657511]

41. Eisenberg RS, Nelson RR. Acad. Med 2002;77:1392-1399. [PubMed: 12480650]

42. Hager J. Methods Enzymol 2006;410:135-168. [PubMed: 16938550]

43. Fox JL. Nat. Biotechnol 1999;17:325-326. [PubMed: 10207872]

44. Rouse R, Hardiman G. Pharmacogenomics 2003;4:623-632. [PubMed: 12943468]

45. Kaiser J. ScienceNOW Daily News. 2008 July 24; 


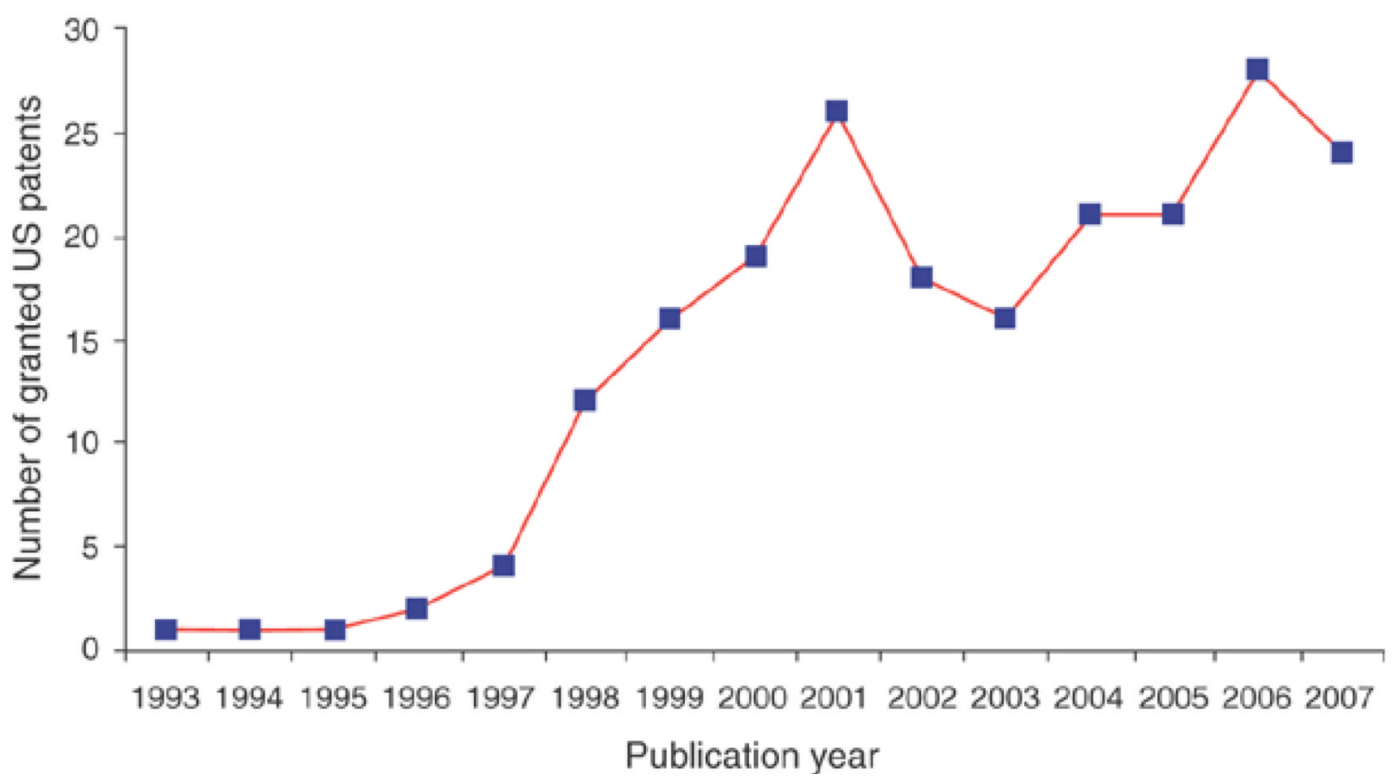

fig 1.

Using Delphion analysis tools, we queried the USPTO database with the following search algorithm: (((zinc finger protein) <in> (TITLE,ABSTRACT,CLAIMS)) OR ((ZFP) <in> (TITLE,ABSTRACT,CLAIMS)) OR ((Zinc finger) <in> (TITLE,ABSTRACT,CLAIMS)) $O R$ ((zinc finger binding protein) <in> (TITLE,ABSTRACT,CLAIMS))). The query was designed to capture any patent containing one or more of the search terms in the "Title" or the "Abstract" or the "Claims" fields. Search terms were selected from keywords specific to ZFPs that frequently appear in a subset of relevant patents (for example, patents owned by Sangamo) and in published articles. Claims-based searches are important to reduce noise, as they avoid terms found only in the description (specification) section of the patent. The claims define the "metes and bounds" of the invention, whereas the description often uses particular terms in the context of providing general background information. All US patents issued on or before 31 December 2007 were included.

Reprinted by permission from Macmillan Publishers Ltd: Nature Biotechnology.

Chandrasekharan S., Kumar S., Valley C.M., Rai A. Proprietary science, open science and the role of patent disclosure: the case of zinc-finger proteins. Nature Biotechnology. 27(2): 140 144. Feb. 2009. Copyright 2009. Available at http://www.nature.com/nbt/journal/v27/n2/abs/nbt0209-140.html 


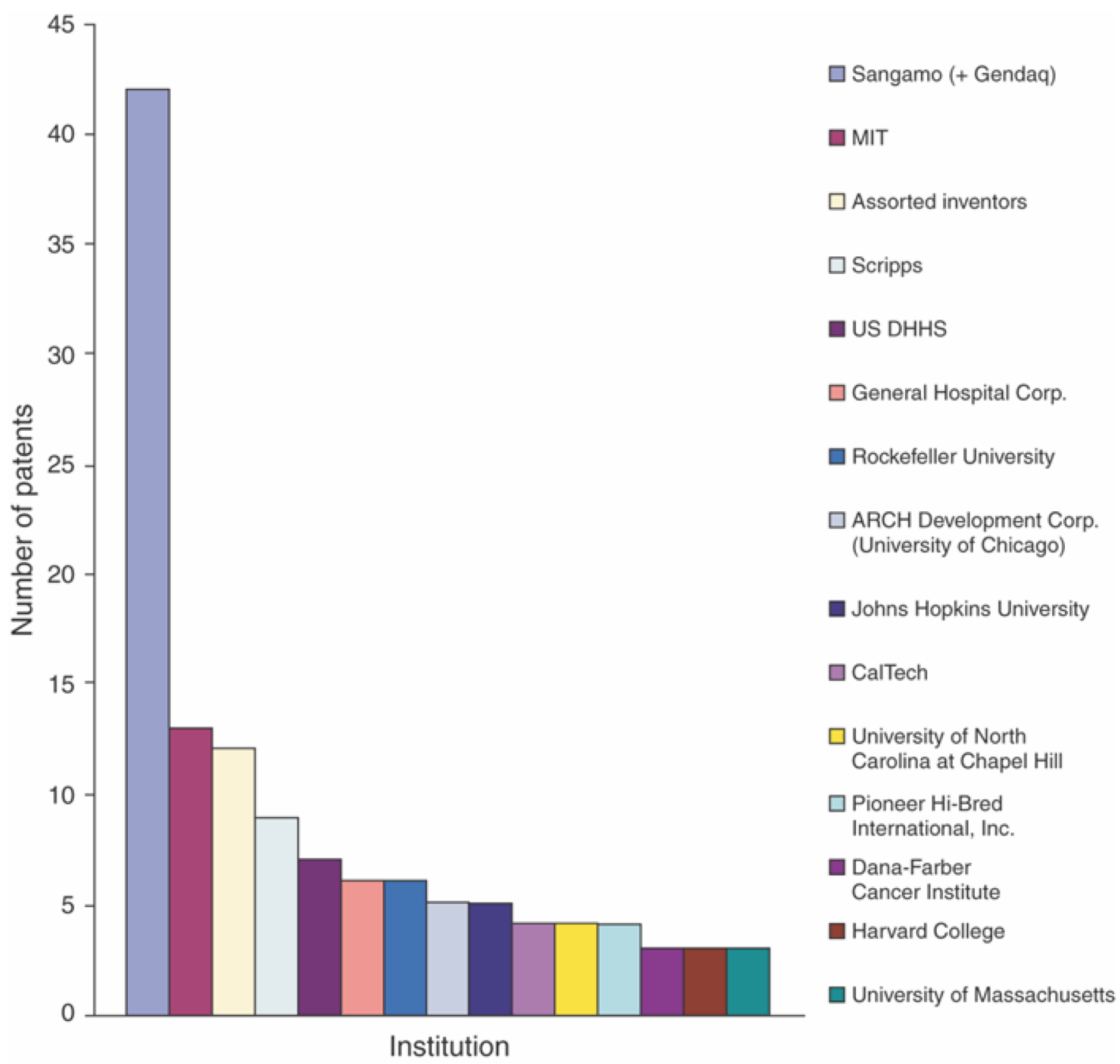

fig 2.

Institutions with three or more US ZFP patents are shown. Data are complete as of 31 December 2007.

Reprinted by permission from Macmillan Publishers Ltd: Nature Biotechnology. Chandrasekharan S., Kumar S., Valley C.M., Rai A. Proprietary science, open science and the role of patent disclosure: the case of zinc-finger proteins. Nature Biotechnology. 27(2): 140 144. Feb. 2009. Copyright 2009. Available at

http://www.nature.com/nbt/journal/v27/n2/abs/nbt0209-140.html 